\title{
Links Between Network Topology and Socioeconomic Framework of Railway Transport: Evidence From Greece
}

\author{
D. Tsiotas \\ Department of Planning and Regional Development, University of Thessaly,Pedion Areos, Volos, 38 334, Greece
}

Received 24 February 2017; Accepted 7 July 2017

\begin{abstract}
This paper studies the Greek railway network (GRAN) by using complex network analysis (CNA) and empirical approach. The study aims to detect the socioeconomic information immanent to the GRAN's topology and to provide insights about how this network serves regional development. The analysis shows that the GRAN's topology complies with the empirical findings on railway networks, which are described by lattice-like characteristics, due to intense spatial constraints, but it outperforms the topology of a lattice and resembles more to a bus-like configuration. The major conclusion, in terms of regional policy, concerns that the GRAN enjoys an effective architecture of bus-topology, but its socioeconomic functionality is not as effective as its topology. Overall, the analysis provides evidence for the utility of applying the network paradigm to transportation research, regional, and spatial studies.
\end{abstract}

Keywords: complex network analysis, spatial networks, bus topology, pattern recognition.

\section{Introduction}

Railway networks are among the oldest land infrastructure networks serving transportation needs with the use of technology (Kurant Thiran, 2006; Barthelemy, 2011; Polyzos et al., 2014). The term "land transportation networks" describes those networks developed on hinterland, which serve transportation without using sea or air modes. Taking into consideration that transportation can be considered as an aspect of human communication submitted to inevitable spatial constraints (Rodrigue et al., 2013, Tsiotas and Polyzos, 2015a), it is obvious that the structure and the shape of such networks diachronically reflects the historic needs of human communication and depends on the corresponding human capabilities to overcome the spatial constraints (Blumenfeld-Lieberthal, 2008; Rodrigue et al., 2013; Tsiotas and Polyzos, 2015a,b). For example, the structure, the geometry and generally the shape of road networks is obviously different today than this existed in the past. Structural differences are due to evolution in vehicle, road, and construction work technologies, whereas shape differences are based on changes in the socioeconomic importance of cities being connected by road networks (Rodrigue et al., 2013; Polyzos et al., 2014).

The study of the specific historic, socioeconomic, and geographic (spatial) conditions surrounding a transportation network contributes to attain a more in-depth knowledge about its structure and functionality and facilitates the process of its modeling. On the other hand, provided that the construction and generally the development of transportation

\footnotetext{
*E-mail address: tsiotas@uth.gr

ISSN: 1791-2377 @ 2017 Eastern Macedonia and Thrace Institute of Technology. All rights reserved. doi:10.25103/iestr.103.23
}

infrastructures is time and money expensive, it can be considered that the form and the topology of transportation networks restrict their further economic and regional development (Blumenfeld-Lieberthal, 2008; Rodrigue et al., 2013; Tsiotas and Polyzos, 2015a,b), implying that the constructed transportation infrastructures lack of the flexibility to rearrange their topology according to their environmental forces, such as in the case of immaterial (i.e. social) networks (Sgroi, 2008), and thus they remain inflexible to the rapid socioeconomic changes (Polyzos et al., 2014; Tsiotas and Polyzos, 2015b).

The elasticity of a transportation network to embody environmental changes depends on its specific characteristics. For example, the structure of land networks is more static than this of maritime or air transport networks, where transportation occurs not in a constructed medium (in contrast to rail or road networks) and thus the spatial constraints are lessen (Rodrigue et al., 2013).

In Greece, transportation through land networks constitutes a major component of the national and regional economy and a considerable developmental drive (Polyzos, 2011), due to geomorphology and geopolitical reasons. From one aspect, Greece intermediates two continents (Europe, Asia) and three seas (Black Sea, Aegean, and Mediterranean), where significant trade and similar potentials are developed. On the contrary, the diverse Greek geomorphology, which is both mountainous and insular, restricts the development of land transportation networks and simultaneously favors the development of alternative (competitive) transportation modes (Tsiotas and Polyzos, 2015a).

Within this framework, this paper studies the interregional Greek Railway Network (GRAN) using complex network analysis (CNA) (Albert and Barabasi, 2002; Barthelemy, 2011) and empirical techniques (Tsiotas and Polyzos, 2015a,b), aiming to mine the socioeconomic 
information that is enclosed in the topology of this network and to evaluate its contribution regional development.

The remainder of this article is organized as follows: section 2 presents the modeling and the methodological framework used in this study, section 3 presents the results of the analysis and discusses them under the regional science perspective, and, finally, in section 4 conclusions are given.

\section{Methodology}

\subsection{Graph modeling and data}

The Greek Railway Network (GRAN) is constructed in the $L$-space representation (Barthelemy, 2011; Tsiotas and Polyzos, 2015a) as an undirected graph $G(V, E)$, where the nodes $V$ represent railway intersections, whereas the edges $E$ represent railway routes running through a single channel without direction changes. Node positioning in the topological map corresponds to the exact coordinates of physical rail intersections, whereas edge length is drawn proportional to their physical distances. The GIS data used for the delineation of GRAN were drafted from the geodata.gov.gr (2010) database, which is s web platform providing open geospatial data and services for Greece and serving as a national open data catalogue. The GRAN was modeled having as spatial weights the kilometric distances between nodes, consisting of

$|V|=n=107$ nodes and equal in number $|E|=n=107$ edges. The physical and its graph representation of GRAN are shown in figure 1.
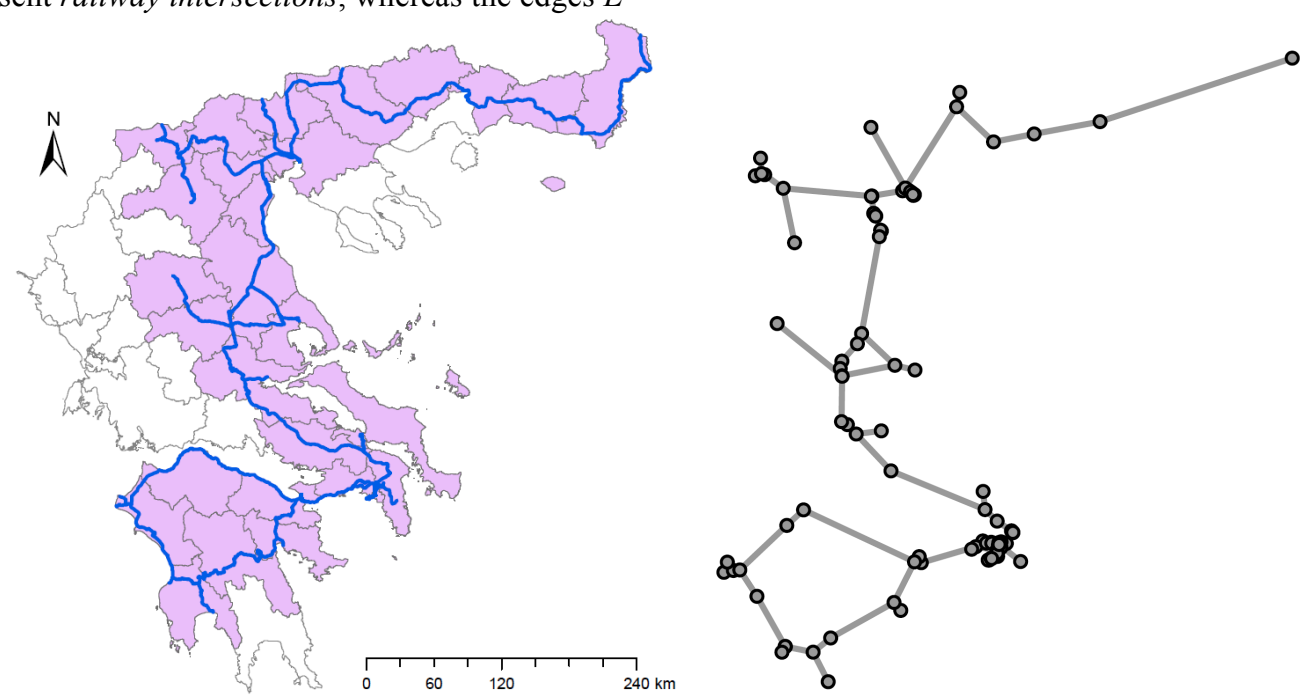

Fig. 1. The physical (left) and graph (right) representation of the Greek Rail Network (GRAN), consisting of $n=107$ nodes and $m=107$ edges. Representations are restricted to the non-insular regions of Greece. Prefectures equipped with railway infrastructure are shown in color.

The GRAN constitutes a disconnected graph including, except of the two major interregional rail network components of the land Greece (the north and south), some also local urban components, such as are the electric, the suburban and the metro railways of the Athens region. The GRAN is modeled as an undirected graph without loss of information, because railway routes are by rule constructed bidirectional. Due to data availability, the GRAN has only spatial weights proportional to kilometric distances of each route.

\subsection{Network measures and descriptives}

A set of network measures and descriptives drafted from Graph Theory (Diestel, 2005) and Network Science (Koschutzki et al., 2005; Blondel et al., 2008; Fortunato, 2010; Barthelemy, 2011; Tsiotas and Polyzos, 2013) are used for the analysis of GRAN. The description of the available measures is shown in brief in table 1 .

Table 1. Network measures used in the analysis

\begin{tabular}{|c|c|c|}
\hline Measure & Description & Math Formula \\
\hline \multicolumn{3}{|l|}{ Notation } \\
\hline$G(V, E)$ & $\begin{array}{l}\text { The graph model of the GRAN, consisting of the } \\
\text { node set } V=V(G) \text { and the edge set } E=E(G) \text {. }\end{array}$ & \\
\hline$n$ & The number of network nodes (vertices) & $n=\sum_{i \in V(G)} i$ \\
\hline$m$ & The number of network edges (links) $e_{i j} \in E(G)$ & $m=\sum_{i, j \in V(G)} \delta_{i j}$, where $\delta_{i j}=\left\{\begin{array}{c}1, \text { if } e_{i j} \in E(G) \\
0, \text { otherwise }\end{array}\right.$ \\
\hline$w_{i j}$ & $\begin{array}{l}\text { The weight of the edge } e_{i j} \text {. For the GRAN, } \\
\text { weights represent spatial (kilometric) distances } \\
w_{i j}=d_{i j} \text {. }\end{array}$ & \\
\hline \multicolumn{3}{|l|}{ Network measures } \\
\hline Graph density $(\rho)$ & $\begin{array}{l}\text { Fraction of the existing connections of the Graph } \\
\text { to the number of the possible connections. } \\
\text { Represents the probability to meet in the GRAN }\end{array}$ & $\rho=\frac{|E(G)|}{\left|E\left(G_{\text {complete }}\right)\right|}=m /\left(\begin{array}{l}n \\
2\end{array}\right)=\frac{2 m}{n \cdot(n-1)}$ \\
\hline
\end{tabular}




\begin{tabular}{|c|c|c|}
\hline Measure & Description & Math Formula \\
\hline & a connected pair of nodes. & \\
\hline $\begin{array}{r}\text { Node Degree } \\
(k)\end{array}$ & $\begin{array}{l}\text { Number of the edges adjacent to a given node, } \\
\text { expressing the node's communication potential. }\end{array}$ & $k_{i}=k(i)=\sum_{j \in V(G)} \delta_{i j}$ \\
\hline $\begin{array}{r}\text { Node (spatial) } \\
\text { strength } \\
(s)\end{array}$ & $\begin{array}{l}\text { The sum of edge distances being adjacent to a } \\
\text { given node. }\end{array}$ & $s_{i}=s(i)=\sum_{j \in V(G)} \delta_{i j} \cdot d_{i j}$ \\
\hline $\begin{array}{c}\text { Average Network's } \\
\text { Degree }\langle k\rangle\end{array}$ & $\begin{array}{l}\text { Mean value of the node degrees } k(i) \text {, with } i \in \\
V(G) \text {. }\end{array}$ & $\langle k\rangle=\frac{1}{n} \cdot \sum_{i=1}^{n} k(i)$ \\
\hline $\begin{array}{r}\text { Closeness } \\
\text { Centrality }\left(C_{i}^{C}\right)\end{array}$ & $\begin{array}{l}\text { Total binary distance } d(i, j) \text { computed on the } \\
\text { shortest paths originating from a given node } i \in \\
V(G) \text { and having destination all the other nodes } j \\
\in V(G) \text { in the network. This measure expresses } \\
\text { the node's reachability in terms of steps of } \\
\text { separation. }\end{array}$ & $C_{i}^{c}=\frac{1}{n-1} \cdot \sum_{j=1, i \neq j}^{n} d_{i j}=\bar{d}_{i}$ \\
\hline $\begin{array}{r}\text { Betweenness } \\
\text { Centrality }\left(C_{k}^{B}\right)\end{array}$ & $\begin{array}{l}\text { Fraction of all shortest paths } \sigma(k) \text { including a } \\
\text { given node } k \text {, to the number } \sigma \text { of all the shortest } \\
\text { paths in the network. }\end{array}$ & $C_{k}^{b}=\sigma(k) / \sigma$ \\
\hline $\begin{array}{r}\text { Clustering } \\
\text { Coefficient }\left(c_{v}\right)\end{array}$ & $\begin{array}{l}\text { Probability of meeting linked neighbors around } \\
\text { the node, which is equivalent to the number of } \\
\text { its connected neighbors } E(i) \text {, divided by the } \\
\text { number of the total triplets shaped by this node. }\end{array}$ & $c_{v}=\frac{\operatorname{triangles}(i)}{\operatorname{triplets}(i)}=\frac{E(i)}{k_{i} \cdot\left(k_{j}-1\right)}$ \\
\hline Modularity $(Q)$ & $\begin{array}{l}\text { Objective function that expresses the potential of } \\
\text { a network to be divided into communities. In its } \\
\text { mathematical formula, } g_{i} \text { is the community of } \\
\text { node } i \in V(G),\left[A_{i j}-P_{i j}\right] \text { is the difference of the } \\
\text { actual minus the expected number of edges } \\
\text { falling between a particular pair of vertices } i, j \in \\
V(G) \text {, and } \delta\left(g_{i}, g_{i}\right) \text { is an indicator function } \\
\text { returning } 1 \text { when } g_{i}=g_{j} \text {. }\end{array}$ & $Q=\frac{\sum_{i, j}\left[A_{i j}-P_{i j}\right] \cdot \delta\left(g_{i}, g_{j}\right)}{2 m}$ \\
\hline $\begin{array}{c}\text { Average Path } \\
\text { Length }\langle l\rangle\end{array}$ & $\begin{array}{l}\text { Average length } d(i, j) \text { of the total of network } \\
\text { shortest paths. }\end{array}$ & $\langle l\rangle=\frac{\sum_{i, j \in V(G)} \delta_{i j} \cdot d_{i j}}{n \cdot(n-1)}$ \\
\hline
\end{tabular}

\subsection{Pattern recognition}

This part of analysis aims at detecting patterns in the topology of the GRAN, which provide further insights about the network structure and dynamics. Such patterns may emerge from a set of approaches (Barabasi and Albert 1999; Albert and Barabasi, 1999; Boccaletti et al., 2006; Barthelemy, 2011), among which those that are applied in this analysis are:

- The examination of the typology of the degree distribution $p(k)$ : this approach provides insights mainly about the existence of the scale-free attribute, which occurs when the degree distribution fits to a power-law curve $f(x)=b x^{-a}$ (Stumpf and Porter, 2012) with exponent within the interval $2<|a|<3$ (Barabasi and Albert 1999; Albert and Barabasi, 1999; Boccaletti et al., 2006), or about the existence of spatial constraints, in cases when the $p(k)$ is peaked (Barthelemy, 2011).

- The examination of sparsity (spy) plots: in this approach (Bishop, 2006) the GRAN's adjacency matrix is visualized using a spy plot representing with dots its nonzero elements. Next, null-models are constructed that are submitted to the $p(k)$-equivalent and $n$-equivalent constraints and their adjacency matrices are also visualized into spyplots. The term $p(k)$-equivalent is used here to describe the available null-models (lattice, random) that have the same degree distribution with the GRAN, whereas the term $n$ equivalent to describe the available null-models (scale-free, small-world) that have the same number of nodes with the empirical network being under examination. Comparisons between spy plots may provide insights about the topological pattern of GRAN.

- The calculation of the omega $(\omega)$ index: this approach was proposed by Telesford et al. (2011) for the approximate small-world detection. According to network theory, the small-world property is defined on a family of graphs, whether the average path length scales logarithmically $\langle l\rangle=O(\log n)$ as $n \rightarrow \infty$ (Xu and Sui, 2007; Barthelemy, 2011; Porter, 2012). Due to the unavailability of studying a family of graphs in empirical cases, the smallworld attribute is detected approximately using the $\omega$ index, which compares the clustering of the network being under examination with that of a $p(k)$-equivalent lattice network $\left(\langle c\rangle_{\text {latt }}\right)$ and the network's path length with that of an $p(k)$ equivalent random network $\left(\langle l\rangle_{\text {rand }}\right)$, according to the following relation:

$\omega=\frac{\langle l\rangle_{\text {rand }}}{\langle l\rangle}-\frac{\langle c\rangle}{\langle c\rangle_{\text {latt }}}$

The null-models are computed using a random algorithm (Maslov and Sneppen, 2002) and the "latticization" algorithm (Rubinov and Sporns, 2010), which both preserve the degree distribution of the original network. Values of $\omega$ 
are restricted to the interval $[-1,1]$, where those close to zero illustrate the small-world attribute, positive values indicate random characteristics and negative indicate more regular or lattice-like characteristics (Tsiotas and Polyzos, 2015b).

- Visualization of network measures' spatial distributions: in this approach, nodes in the network's geographical map are colored proportionally to the values they have for a certain measure or attribute (Heymann, 2014). This visualization contributes detecting the spatial patterns of the network measures and the differences in their spatial distributions (Tsiotas, 2017).

- Correlations between connectivity and traffic: correlations between degree $(k)$ with betweenness centrality $\left(C^{b}\right)$ and strength $(s)$, namely $\left(k, C^{b}\right)$ and $(k, s)$ respectively, are broadly used to detect homogeneity between connectivity and network traffic. Since GRAN has only spatial weights, the $(k, s)$ correlation does not suffice to provide traffic information, whereas the $\left(k, C^{b}\right)$ correlation does it indirectly. Further, provided that the node-degree $(k)$ is a discrete measure, the cases $\left(k, C^{b}\right)$ and $(k, s)$ are being classified into $p$ groups $\left(k=i,\left\{C^{b}: k=i\right\}\right)$ and $(k=i,\{s: k=i\})$, with $i=1,2, \ldots, k_{\max }=p$. Consequently, power-law fittings are applied to average $C^{b}$ and $s$ values per degree-case $(k=i)$, namely to pairs $\left(k=i,\left\langle\left\{C^{b}: k=i\right\}\right\rangle\right)$ and $(k=i,\langle\{s: k=i\}\rangle)$. When $b_{(k, C b)}>1$ it implies that hubs are those undertaking the biggest proportion of the network traffic, whereas $b_{(k, s)}>1$ it illustrates that hubs undertake the distant communication (Barthelemy, 2011).

\subsection{Empirical Analysis}

Empirical analysis is performed to a set of structural variables of the railway network, being compared with other available spatial, economic, demographic, and tourism variables. All variables were edited to refer to regional scale (NUTS II), since the nodes in their physical scale do not have any practical physical or regional economic utility. The variables participating in the empirical analysis are shown in table 2 .

Table 2. Variables ${ }^{*}$ participating in empirical analysis of GRAN

\begin{tabular}{|c|c|c|c|}
\hline No & Symbol & Description & Data Reference \\
\hline \multicolumn{4}{|c|}{ Network infrastructure variables } \\
\hline 1. & GRN & $\begin{array}{l}\text { Road Network Length: The total road network length included in } \\
\text { each prefecture. }\end{array}$ & $\begin{array}{l}\text { OKXE (2005); own } \\
\text { elaboration }\end{array}$ \\
\hline 2. & $G R N_{D E N S I T Y}$ & $\begin{array}{l}\text { Road Network Density: The road network density of each } \\
\text { prefecture, defined as the fraction of the total road length included } \\
\text { in a prefecture to the prefecture's area. }\end{array}$ & $\begin{array}{l}\text { OKXE (2005); own } \\
\text { elaboration }\end{array}$ \\
\hline \multirow[t]{2}{*}{3.} & $G R A N_{L E N G T H}$ & $\begin{array}{l}\text { Railway Network Length: The total railway network length } \\
\text { included in each prefecture. }\end{array}$ & $\begin{array}{l}\text { OKXE (2005); own } \\
\text { elaboration }\end{array}$ \\
\hline & $G R A N_{D E N S I T Y}$ & $\begin{array}{l}\text { Railway Network Density: The railway network density of each } \\
\text { prefecture, defined as the fraction of the total railway length } \\
\text { included in a prefecture to the prefecture's area. }\end{array}$ & $\begin{array}{l}\text { OKXE (2005); own } \\
\text { elaboration }\end{array}$ \\
\hline 1. & $A R E A$ & Prefecture Area: The area of each prefecture $\left(\right.$ in $\left.\mathrm{km}^{2}\right)$. & $\begin{array}{l}\text { OKXE (2005); own } \\
\text { elaboration }\end{array}$ \\
\hline 2. & PORTS & Number of Ports: Number of sea ports included in each prefecture. & $\begin{array}{l}\text { Tsiotas and Polyzos } \\
\text { (2014) }\end{array}$ \\
\hline \multicolumn{4}{|c|}{ Spatio-economic variables } \\
\hline 3. & $I P P$ & $\begin{array}{l}\text { Indirect Population Potential: complex measure, describing the } \\
\text { volume of economic activities that a prefecture can access. }\end{array}$ & Polyzos (2011) \\
\hline 4. & $D P P$ & $\begin{array}{l}\text { Direct Population Potential: complex measure, describing the } \\
\text { volume of economic activities that are developed within a } \\
\text { prefecture. }\end{array}$ & Polyzos (2011) \\
\hline \multicolumn{4}{|c|}{ Economic variables } \\
\hline 5. & $G D P$ & $\begin{array}{l}\text { Gross Domestic Product: the percentage contribution of each } \\
\text { prefecture to the country's GDP. }\end{array}$ & Polyzos (2011) \\
\hline 6. & $A_{S E C}$ & $\begin{array}{l}\text { A-Sector Specialization: the participation of a prefecture's primary } \\
\text { product to the national GDP, for the year } 2013 \text {. }\end{array}$ & $\begin{array}{l}\text { Tsiotas and Polyzos } \\
\text { (2014) }\end{array}$ \\
\hline 7. & $C_{S E C}$ & $\begin{array}{l}\text { C-Sector Specialization: the participation of a prefecture's tertiary } \\
\text { product to the national GDP, for the year } 2013 \text {. }\end{array}$ & $\begin{array}{l}\text { Tsiotas and Polyzos } \\
\text { (2014) }\end{array}$ \\
\hline 8. & $A G R_{I N V}$ & $\begin{array}{l}\text { Agro-industrial Investments: per capita investments in agro- } \\
\text { industry occurred in a prefecture for the period } 2004-2008 \text {. }\end{array}$ & Polyzos et al. (2015) \\
\hline 9. & $R P D$ & $\begin{array}{l}\text { Regional Productivity Dynamism: complex index, calculated on the } \\
\text { levels of employment and productivity structures for a given } \\
\text { prefecture. }\end{array}$ & Polyzos et al. (2015) \\
\hline \multicolumn{4}{|c|}{ Socio-demographic variables } \\
\hline 10. & $P O P$ & $\begin{array}{l}\text { Regional Population: the population of each prefecture according } \\
\text { to the } 2011 \text { national census. }\end{array}$ & $\begin{array}{l}\text { Tsiotas and Polyzos } \\
\text { (2014) }\end{array}$ \\
\hline 11. & WELF & Welfare Index: it describes the level of welfare of each prefecture. & Polyzos (2011) \\
\hline 12. & $E D U$ & $\begin{array}{l}\text { Educational Index: it describes the educational level of citizens in } \\
\text { each prefecture. }\end{array}$ & Polyzos (2011) \\
\hline 13. & $U R B$ & $\begin{array}{l}\text { Urbanization Index: it represents the population of each } \\
\text { prefecture's capital city. }\end{array}$ & Polyzos et al. (2015) \\
\hline
\end{tabular}




\begin{tabular}{|c|c|c|c|}
\hline No & Symbol & Description & Data Reference \\
\hline 14. & $T_{G D P}$ & $\begin{array}{l}\text { Tourism Specialization: the participation of a prefecture's tourism } \\
\text { product to the national GDP, for the year } 2013 \text {. }\end{array}$ & $\begin{array}{l}\text { Tsiotas and Polyzos } \\
(2015 \mathrm{a})\end{array}$ \\
\hline 15. & $R$ & $\begin{array}{l}\text { TALC Growth Coefficient }(S T / T) \text { : Tourism Area Life Circle } \\
\text { (TALC) Growth Coefficient, expressing the level of saturation of a } \\
\text { prefecture in terms of per capita overnight-stayings recorded for } \\
\text { this prefecture. }\end{array}$ & Polyzos et al. (2013) \\
\hline 16. & $R_{T}$ & $\begin{array}{l}\text { TALC Growth Coefficient (ST): Tourism Area Life Circle (TALC) } \\
\text { Growth Coefficient, expressing the level of saturation of a } \\
\text { prefecture in terms of overnight-stayings recorded for this } \\
\text { prefecture. }\end{array}$ & Polyzos et al. (2013) \\
\hline 17. & $R_{S T}$ & $\begin{array}{l}\text { TALC Growth Coefficient (T): Tourism Area Life Circle (TALC) } \\
\text { Growth Coefficient, expressing the level of saturation of a } \\
\text { prefecture in terms of number of tourists visiting this prefecture. }\end{array}$ & Polyzos et al. (2013) \\
\hline
\end{tabular}

* The elements included in each variable are scores of prefectures referring to a certain attribute/ characteristic

In the part of empirical analysis, an independent-samples $t$-test is applied to the set of the available variables. This test compares the difference of the means $\mu_{\alpha}$ and $\mu_{\beta}$ between two discrete groups $\left\{X_{\alpha}, X_{\beta}\right\}$ that originate from the same variable $X$. The null hypothesis states that these means are statistically equal $\left(H_{\mathrm{o}}: \mu_{\alpha}=\mu_{\beta}\right)$, whereas the alternative hypothesis expresses that they are different $\left(H_{1}: \mu_{\alpha} \neq \mu_{\beta}\right)$. The algorithm of the test applies a sub-procedure with the Levene's test to examine whether the variances between these two groups are equal and provides separate results per case (separate/unpooled and pooled variances), which are valid depending on their significance (Hays, 1981; Norusis, 2004).

In this analysis, the groups are formulated according to

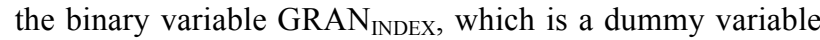
assigning the value one (1) to the prefectures that include railway infrastructures and zero $(0)$ otherwise. Provided that the railway network does not cover the total area of the Greek territory (serving almost the half $-26 /^{51}$ - regions), the purpose of applying this test is to detect whether the prefectures with railway network show different socioeconomic performance in regard to the variables being under examination. Specifically, the cases rejecting the null hypothesis (concluding that $\mu_{\alpha} \neq \mu_{\beta}$ ) interprets that the prefectures having railway transportation infrastructures either show better or worse performance (depending on the sign of the difference $\mu=\mu_{\alpha}-\mu_{\beta}$ ) than those without railway connection, in regard to concept of variable $X$.

\section{Results and Discussion}

\subsection{Calculation of network measures}

The network measures calculated for the GRAN are shown in table 3 , where it is observed that GRAN is composed by 8 connective components, without including any isolated nodes $\left(k_{\mathrm{GRAN}, \min } \neq 0\right)$ and self-connections $\left(n\left(e_{i i} \in E\right)=0\right)$. The maximum degree of this railway network is $k_{\mathrm{GRAN}, \max }=3$, whereas its average degree is $\langle k\rangle_{\mathrm{GRAN}}=2$. This result complies with the corresponding value $\langle k\rangle \approx 2.1$ of the Swiss railway network that was studied by Kurant and Thiran (2006).

Table 3. Network measures of the GRAN

\begin{tabular}{|c|c|c|c|}
\hline Measure & Symbol & Unit & Value \\
\hline Nodes & $n$ & $\#^{(\mathrm{a})}$ & 107 \\
\hline Edges & $m$ & $\#$ & 107 \\
\hline Self-connected nodes & $n\left(e_{i i} \in E\right)$ & \# & - \\
\hline Isolated nodes & $n_{k=0}$ & \# & - \\
\hline Connected components & $\alpha$ & \# & 8 \\
\hline Maximum degree & $k_{\max }$ & \# & 3 \\
\hline Minimum degree & $k_{\min }$ & $\#$ & 1 \\
\hline Average node degree (binary) & $\langle k\rangle$ & \# & 2 \\
\hline$-/ /-$ (weighted) & $\left\langle k_{w}\right\rangle$ & $\mathrm{km}$ & 45.783 \\
\hline Average nearest neighbor degree (binary) & $\left\langle k_{N(v)}\right\rangle$ & \# & 1.338 \\
\hline$-/ /-$ (weighted) & $\left\langle k_{N(v), w}\right\rangle$ & $\mathrm{km}$ & 30.618 \\
\hline Average edge length & $\left\langle d\left(e_{i j}\right)\right\rangle$ & $\mathrm{km}$ & 24.293 \\
\hline Total edge length & $\sum_{i j} d\left(e_{i j}\right)$ & $\mathrm{km}$ & $2 ’ 259.2$ \\
\hline Average path length (binary) & $\langle l\rangle$ & \# & 9.501 \\
\hline -//- (weighted) & $\langle l\rangle$ & $\mathrm{km}$ & 132.42 \\
\hline Network diameter (binary) & $d_{b i n}(G)$ & \# & 30 \\
\hline
\end{tabular}




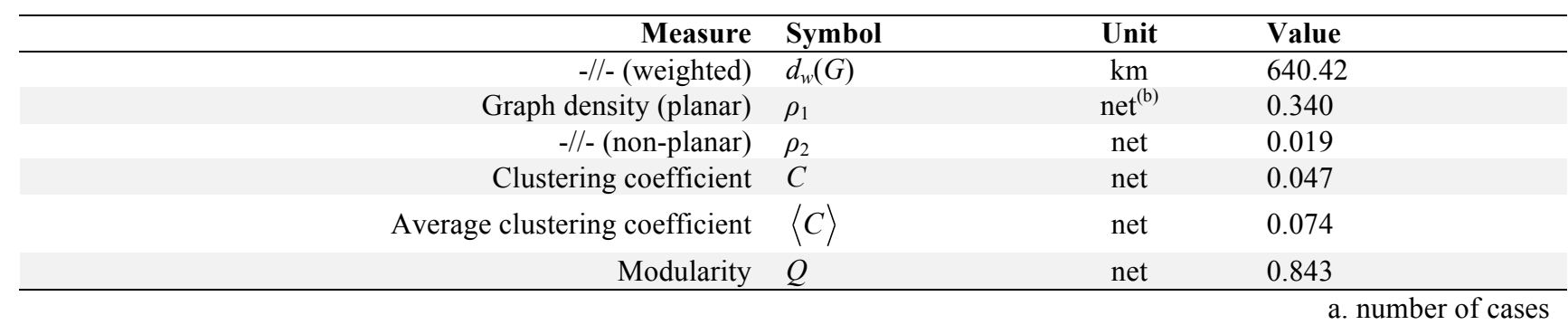

b. dimensionless number

The average weighted degree of GRAN is $\left\langle k_{w}\right\rangle$ $=45.783 \mathrm{~km}$ and it expresses the total length of railway connections attached on average to a node of this network. The average neighbor degree, which is defined as the average of the average degrees $\left(\left\langle k_{j}\right\rangle\right)$ that are computed along the neighbor-sets $N\left(v_{i}\right)$ for every node $v_{i} \in V(G)$, is

$\left\langle k_{N\left(v_{i}\right)}\right\rangle_{\text {GRAN }}=1.338$. This expresses that, on average, a node is connected with neighbors of average degree equal to 1.338 connections.

According to an observation made by Tsiotas and Polyzos (2015) during the study of the Greek Aviation Network (GAN), which concerns the relation between the measures of average neighbor degree and average degree, the inequality $\left\langle k_{N(v)}\right\rangle_{\text {GRAN }}<\langle k\rangle_{G R A N}$ expresses that it is more possible for a randomly chosen network node to be of higher degree than its neighbors. For the GRAN's topology, this inequality implies that the majority of nodes are connected with the maximum (or close to the maximum) degree and thus it is more probable to meet a hub in this network, where the existence of a spoke connection among its neighbors contributes to the decrease of the average nearest neighbor degree.

Additionally, the average weighted nearest neighbor degree of GRAN is $\left\langle k_{N(v), w}\right\rangle_{G R A N}=30.618 \mathrm{~km}$ and expresses the total kilometric (spatial) distance of the edges adjacent to a node (total length of neighbor connections). The previous inequality between average degree and average nearest neighbor degree is also valid and in the kilometric-weighted case $\left(\left\langle k_{N(v), w}\right\rangle_{\text {GRAN }}<\left\langle k_{w}\right\rangle_{\text {GRAN }}\right)$, illustrating that the topology of GRAN resembles to this of a bus. In such a topology, the nodes that are arranged along the central bus-axis are usually hubs and distant to each other, whereas the hubs are connected in periphery with spokes that are closer than the inter-hub distances.

The average edge length $\left\langle d\left(e_{i j}\right)\right\rangle_{\text {GRAN }}$ of GRAN expresses that the average railway route until to meet a crossway is $24.293 \mathrm{~km}$, whereas the total length of the network is $\sum_{i j} d\left(e_{i j, G R A N}\right)=2 ' 259.2 \mathrm{~km}$. The average path length of GRAN expresses that the path between any pair of nodes is on average $\langle l\rangle_{\text {GRAN }}=9.501$ edges and distant $d(\langle l\rangle)$ $=132.42 \mathrm{~km}$. In terms of regional science, the measure $\langle l\rangle_{\text {GRAN }}$ is related to the general transportation cost (Tsiotas and Polyzos, 2014, 2015a) within the GRAN and it is of order $\mathrm{O}(\sqrt{n})=\sqrt{107} \approx 10.344$ that corresponds to a twodimensional lattice network of the same number of nodes (see Barthelemy, 2011). This result obviously reflects the constraints of planarity, which are immanent in the GRAN due to its lattice-like structure.

Next, the longest binary path in the GRAN is 30 steps (edges), whereas the longest kilometric is $640.42 \mathrm{~km}$. Whether considering the GRAN as a planar graph, its density is $\rho_{1}=0.340$, expressing that this railway network includes the $34 \%$ of the possible connections that can be developed in the plane for the given number of nodes $n_{\text {GRAN }}$. In contrast, whether considering the GRAN as a non-planar graph, its density is $\rho_{2}=0.019$, expressing that this network includes the $1.9 \%$ of the possible connections that can be developed in the space for the $n_{\text {GRAN }}$ nodes.

The clustering coefficient of GRAN equals to $C_{\mathrm{GRAN}}=0.047$ and average node clustering coefficient is $\langle C\rangle_{\text {GRAN }}=0.074$, which is significantly greater than this of an ER-random graph $\langle C\rangle_{E R} \sim 1 / n=1 / 107=9.3 \cdot 10^{-3}$. Finally, the GRAN's modularity is $Q_{\mathrm{GRAN}}=0.843$, expressing that this network has a great potential to be divided into communities.

\subsection{Pattern recognition}

The initial approach for the GRAN's pattern recognition is the examination of the degree distribution typology, according to the scatter plots $(k, n(k))$ shown in metric and logarithmic scale in figure 2. Due to lack of $(k, n(k))$ cases, the procedure of fitting a curve to these data is not a safe approach for pattern recognition of the railway network (Stumpf and Porter, 2012; Tsiotas and Polyzos, 2015a). However, the obvious non-collinear arrangement of the $p(k)$ cases shown in the logarithmic scale (figure 2) illustrates that the typology GRAN does not correspond to a power-law pattern and thus it is far from to be described by the scalefree or small-world property. Further, the GRAN's degree distribution $p(k)$ in the metric scale shows a peak at the value $k=2$, which complies with the general empirical observation ruling the railway and the broader spatial networks submitted to intense spatial constraints (Barthelemy, 2011). 

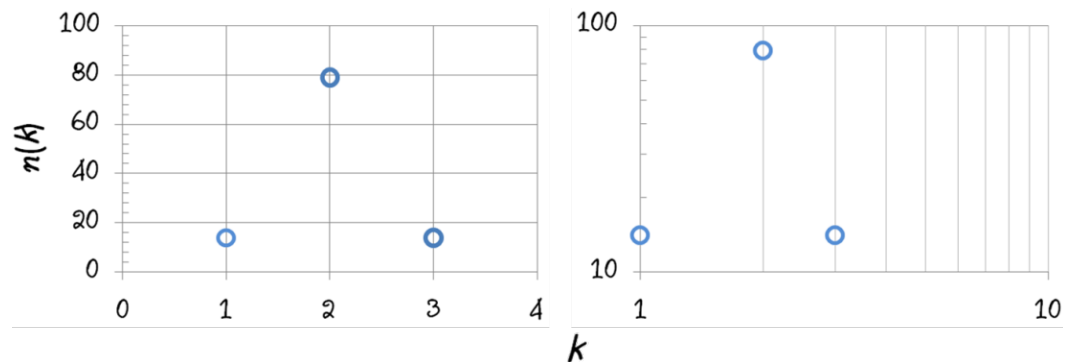

Fig. 2. Scatter plots $(k, n(k))$ shown in metric (left) and logarithmic (right) scale, illustrating the typology of the GRAN's degree distribution $p(k)$.

At next, the spy plots (Bishop, 2006) are constructed from the adjacency matrices (a) of the GRAN, and of four node-equivalent ( $n=107=$ constant) networks (null-models), which have the (b) scale-free, (c) lattice, (d) small-world, and (e) random network property, respectively (figure 3). Among these, the null-models (c) and (e) have in addition the same degree distribution $p(k)$ with GRAN. The comparison of the GRAN's spy plot with the (b)-(e) nullmodels illustrates that the sparsity pattern of the network being under examination resembles more with these of (c) lattice network and (e) random graph. Provided that the GRAN represents a railway network, the most proper typology between these two is this of the lattice network. This deduction is expected to be verified at next, with the calculation of the omega $(\omega)$ index, which is proposed by Telesford et al. (2011) and examines approximately whether the network is ruled by the small-world property or it is described by random-like or lattice-like characteristics

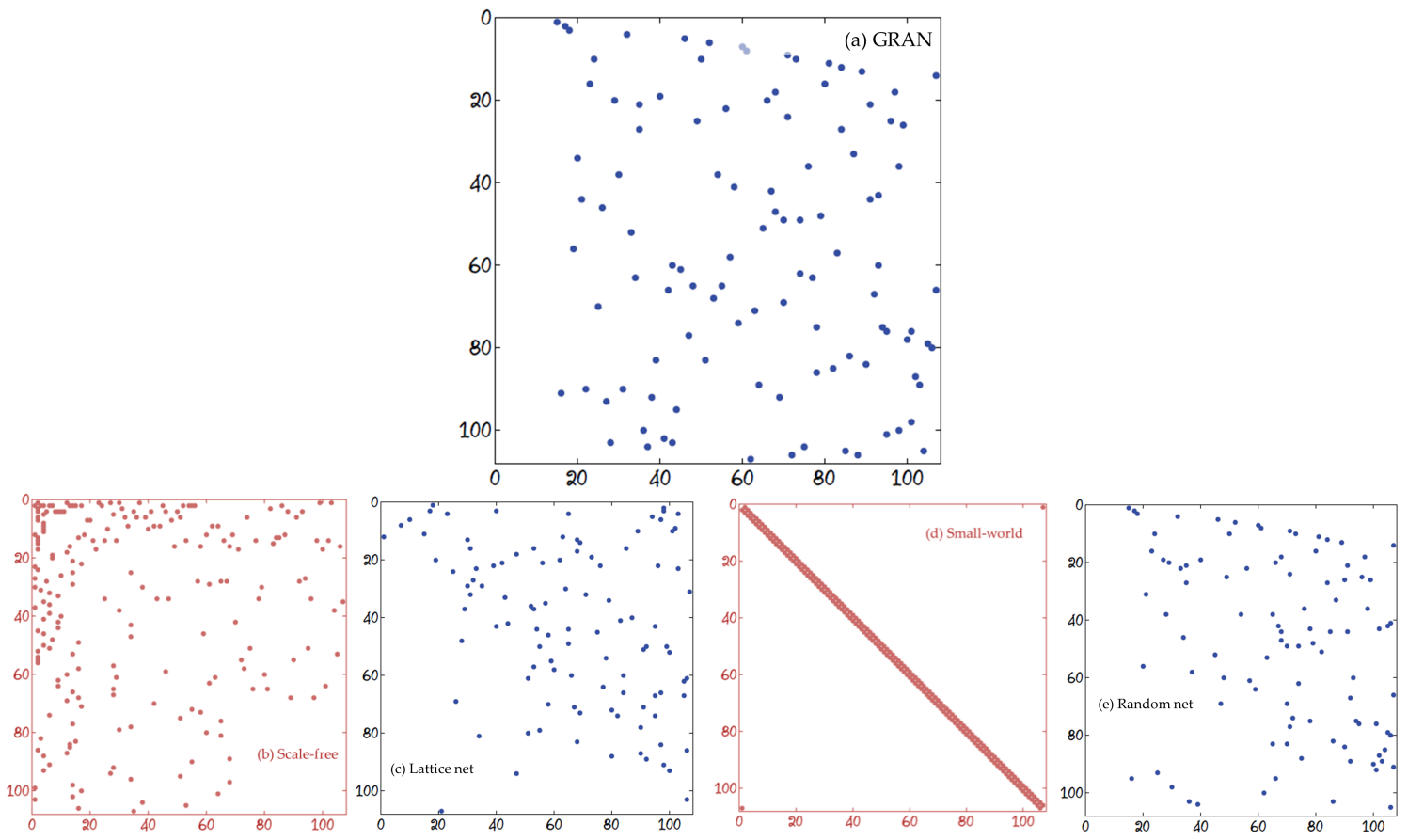

Fig. 3. Sparsity (spy) plots constructed from the adjacency matrices (a) of GRAN and of four node-equivalent $(n=107=$ constant) networks, which have the (b) scale-free, (c) lattice, (d) small-world, and (e) random network property, respectively. Among these null-models, the cases (c) and (e) have in addition the same degree distribution $p(k)$ with GRAN.

The results of the approximate small-world detection (omega index calculation) for the GRAN are shown in table 4 . The index has a negative value $\omega=-0.121$, indicating the existence of lattice-like characteristics, which is however closer to the center than to the borders of the index's image $I_{\omega}=[-1,1]$, namely $|0-\omega|=0.121<|1-\omega|=0.879<|-1-\omega|=1.121 . \quad$ This observation interprets that the GRAN is obviously more probable to be of lattice-like than of random-like characteristics, but such characteristics are not intense enough to define this empirical network as a pure lattice. Additionally, this interpretation complies with the previous findings stating that the topology of GRAN resembles to the topology of a bus, which is structurally an elegant topology, obviously not a random, and probably closer to this of a small-world than to a lattice network ( $|0-\omega|=0.121<|1-\omega|=0.879)$.

$\langle c\rangle_{\text {latt }}$

Table 4.Results of the approximate small-world detection (omega index calculations) for the GRAN

\begin{tabular}{cccccc}
\hline Measure & $\langle c\rangle$ & & $\langle l\rangle$ & $\langle l\rangle_{\text {rand }}$ & $\boldsymbol{\omega}^{*}$ \\
\hline & $\begin{array}{c}0.07 \\
4\end{array}$ & $\begin{array}{c}0.07 \\
4\end{array}$ & $\begin{array}{c}9.50 \\
1\end{array}$ & 8.356 & $\begin{array}{c}\mathbf{0 . 1 2 0} \\
\mathbf{5}\end{array}$ \\
$\begin{array}{c}\text { Indicatio } \\
\mathrm{n}\end{array}$ & & \multicolumn{4}{c}{ lattice-like characteristics } \\
\hline
\end{tabular}


. according to relation (3)

Afterwards, the spatial distributions of the fundamental topological and centrality network measures of the GRAN (degree, betweenness, closeness, clustering, modularity, and strength) are visualized to the maps of figure 4 and being examined. First, the spatial distribution of degree $(k)$ (figure 4a) seems to verify the previously detected bus topology, since the network hubs (shown in bigger size) in the GRAN are arranged along a basic axis (i.e. the bus), whereas the other nodes (shown in smaller size) are arranged vertically to the bus, in branches. Next, the central nodes in respect to betweenness centrality $\left(C^{b}\right)$ (figure $4 b$ ) are more concentrated than the degree hubs. In particular, the $C^{b}$-hubs are arranged along a smaller length of the bus-route, which are located in the center of the GRAN. The spatial distribution of closeness centrality $\left(C^{c}\right)$ (figure $4 \mathrm{c}$ ) shows an expected pattern, whether taking into consideration the network's cutoff at the location of Attica. According to this pattern, the closeness-hubs are also being arranged along the bus-route and are close to the geographical centers of each network components.

At next, the spatial distribution of the clustering coefficient $(C)$ (figure 4d) presents a rather simple pattern. High $C$-values are located at the central part of the north (above Attica) and south (at Peloponnesus) components of the GRAN, which concern the regions of Veroia-
Thessaloniki and Messinia, respectively. In this case, the $C$ hubs are also geographically dependent and are distributed along the bus-axis. In contrast, the spatial distribution of the measure of modularity classification $(Q)$ (figure $4 \mathrm{e}$ ) follows a complex pattern, which however shows a geographical consistency. In particular, the north GRAN's component is divided to six communities, the south is separated to two, and this of Attica forms six communities.

Except from the region of Attica, which includes the majority of the GRAN's physical components, the communities shaped in the other two physical components (north and Peloponnese) of this railway network seem to be controlled by geographical criteria, complying with other empirical findings on railway networks (Sen et al., 2003, Barthelemy, 2011). Finally, the spatial distribution of the measure of spatial strength $(s)$ (figure $4 \mathrm{f}$ ) shows an inverse pattern in comparison with this of $C^{c}$, which is expected whether taking into consideration the calculation formula of $s$. Particularly, since $s$ is computed by summing distances of edges adjacent to a given node, high $s$-values describe nodes that are more distant to their neighbors than others. In contrast, high values of $C^{c}$ describe nodes that are closer to all the others in the network. Geographically, the $s$-hubs are located at the northern part of the GRAN, in the region of Thrace including the longest network edge.

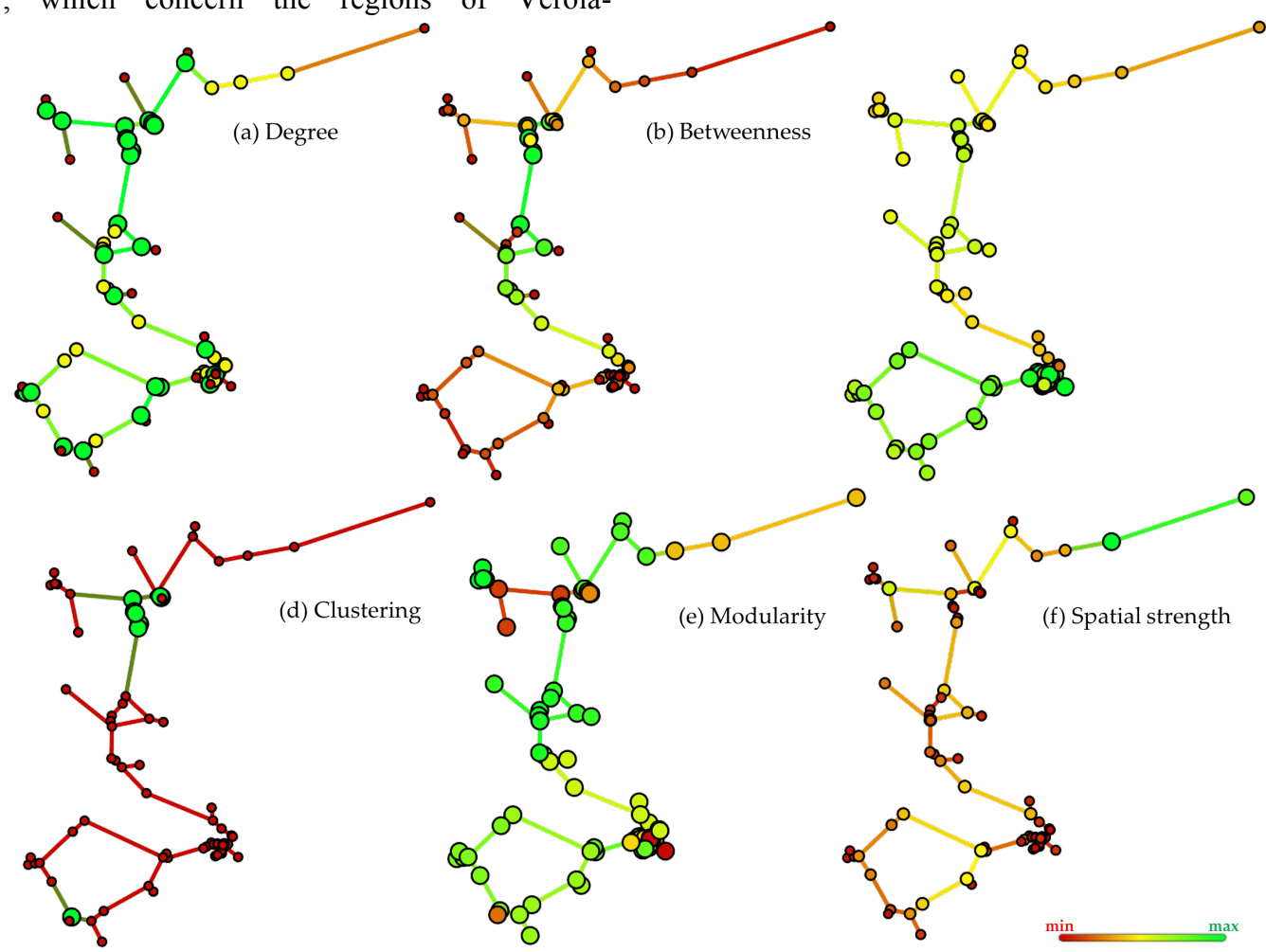

Fig. 4. Spatial distribution of the GRAN's measures: (a) degree, (b) betweenness, (c) closeness, (d) clustering, (e) modularity classification, and (f) spatial strength.

At the last part of the GRAN's topological analysis the correlations of degree with the measures of betweenness centrality $\left(k, C^{b}(k)\right)$ and spatial strength $(k, s(k))$ are examined, based on the scatter-plots of figure 5 . 

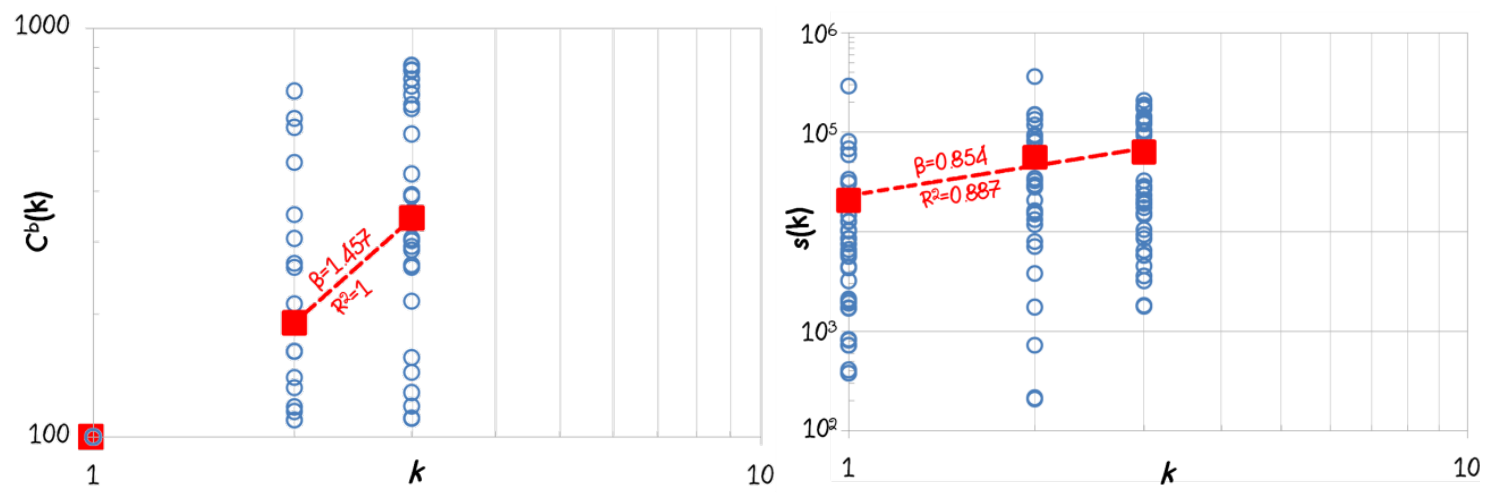

Fig. 5. Scatter plots of (left) degree and betweenness centrality $\left(k, C^{b}\right)$ and (right) degree and spatial strength $(k, s)$ for the GRAN. Square values represent averages for each degree class.

Despite the obvious deficiency of cases, the fittings applied to the pairs $\left(k_{i},\left\langle\left. C^{b}\right|_{k=k_{i}}\right\rangle\right)$ and $\left(k_{i},\left\langle s_{k=k_{i}}\right\rangle\right)$, where $i=2,3$, may provide some useful insights. On the one hand, the relation $\left\langle\left. C^{b}\right|_{k=k_{i}}\right\rangle=f(k)$ has a power-law exponent $\beta_{\operatorname{GRAN}(k-}$ $C b)=1.457$, which is closer to the magnitude of the Global Cargo Ship Network (GCSN), where $\beta_{\mathrm{GCSN}(k-\mathrm{Cb})}=1.66(\mathrm{Hu}$ and Zhu, 2009) or the North American Air-Transportation Network (NAAN) (Barrat et al., 2005), where $\beta_{\mathrm{NAAN}(k-C b)} \sim 1.2$ than of classical road networks having an exponent around $\beta_{\text {ROADNETS }(k-C b)} \sim 1.9$ (Barthelemy, 2011). This observation implies that, although the GRAN is a land network, the forces controlling the relationship between hubs of connectivity $(k)$ and traffic $\left(C^{b}\right)$ are more similar to networks with "smoother" spatial constraints, such as maritime and air transport networks, than of land transport networks. This interpretation illustrates that the bus topology ruling a railway network is more optimum than this of lattice-like topology describing the majority of road networks. On the other hand, the relation $\left\langle s_{k=k_{i}}\right\rangle=f(k)$, between network degree $k$ and average strength $\left\langle s_{k=k_{i}}\right\rangle$, has a power-law exponent $\beta_{\operatorname{GRAN}(k-s)}=0.854$, which is closer to the magnitude of the road network cases, where $\beta_{\text {ROAD_NETS }(k-s)} \sim 0.7-0.9$, than of maritime $\left(\beta_{\mathrm{WAN}(k-s)}=1.3\right)$ or air transport networks (Barthelemy, 2011). This is in contrast to the previous observation, implying that the forces controlling the relationship between hubs of connectivity $(k)$ and spatial strength $(s)$ of the GRAN are more similar to those of land- transport networks than of networks with lessened spatial constraints. Overall, the previously examined correlations illustrate that the bus-like topology of GRAN is more optimum in terms of traffic-management $\left(k_{i},\left\langle\left. C^{b}\right|_{k=k_{i}}\right\rangle\right)$ than of distance-management $\left(k_{i},\left\langle s_{k=k_{i}}\right\rangle\right)$, comparatively to the road network transportation.

\subsection{Empirical Analysis}

This section empirically examines whether the railway infrastructure of Greece is related to other regional socioeconomic measures and indices. An independent samples t-test is applied on the available variables of table 2 , which are grouped according to the dummy variable GRAN $_{\text {INDEX }}$ distinguishing the prefectures with railway infrastructures (1) and not (0). Significant cases indicate that these groups $\left(\mathrm{GRAN}_{\mathrm{INDEX}}=1\right.$ and 2$)$, within the examined variable, are statistically different, implying that the existence of railway infrastructures is related to the observed difference and thus they may suggest a determining factor for this variable. The test is applied twice, first to variables including the metropolitan regions of Attica and Thessaloniki $(n=51)$, which are the only exceeding the population threshold of 1.000 .000 people, and second to variables excluding the metropolitan cases $(n=49)$. This approach targets to capture any latent effects of these metropolitan regions to the available variables. The results of the empirical analysis are shown in table 5 .

Table 5. Independent samples $t$-test results for the equality of means among the variables of GRAN ${ }^{(a)}$

\begin{tabular}{|c|c|c|c|c|c|c|c|c|c|}
\hline \multirow[b]{3}{*}{$\begin{array}{r}\text { Hypothesis of } \\
\text { equal variables } \\
s_{\alpha}=s_{\beta} \text { : }\end{array}$} & \multirow{2}{*}{\multicolumn{2}{|c|}{$\begin{array}{l}\text { Levene's test } \\
\text { for the equality } \\
\text { of variances }\end{array}$}} & \multicolumn{7}{|c|}{ Independent samples $t$-test for the equality of means } \\
\hline & & & \multirow[b]{2}{*}{$\mathrm{t}$} & \multirow[b]{2}{*}{ d.f..$^{(b)}$} & \multirow[b]{2}{*}{ Sig. ${ }^{(c)}$} & \multirow{2}{*}{$\begin{array}{c}\text { Mean } \\
\text { difference } \\
\langle\Delta \mu\rangle\end{array}$} & \multirow[b]{2}{*}{$\begin{array}{l}\text { SE of the } \\
\text { difference }\end{array}$} & \multicolumn{2}{|c|}{$\begin{array}{l}95 \% \text { confidence interval } \\
\text { for the mean difference }\end{array}$} \\
\hline & $\mathrm{F}$ & Sig. & & & & & & $\begin{array}{l}\text { Lower } \\
\text { limit }\end{array}$ & Upper limit \\
\hline \multicolumn{10}{|c|}{ VARIABLE: GRN $N_{L E N G T H}($ Road network length of each prefecture) } \\
\hline assumed & .000 & .999 & -1.972 & 49 & .054 & $-163 ’ 290.5$ & $82^{\prime} 800.42$ & $-329^{\prime} 684.2$ & 3'103.21 \\
\hline assumed & .000 & .997 & -1.714 & 47 & .093 & $-146 ’ 268.6$ & $85^{\prime} 332.90$ & $-317^{\prime} 936.2$ & $25 ’ 399.07$ \\
\hline \multicolumn{10}{|c|}{ AREA (Prefecture's area) } \\
\hline assumed & .171 & .681 & -2.866 & 49 & .006 & -935.61 & 326.49 & $-1 ' 591.72$ & -279.49 \\
\hline assumed & .317 & .576 & -3.008 & 47 & .004 & -988.80 & 328.67 & $-1 ' 650.00$ & -327.60 \\
\hline \multicolumn{10}{|c|}{$G R N_{D E N}($ Road network density of each prefecture $)$} \\
\hline assumed & .009 & .927 & .726 & 49 & .471 & 22.21 & 30.59 & -39.26 & 83.68 \\
\hline assumed & 2.285 & .137 & 2.400 & 47 & .020 & 47.09 & 19.62 & 7.63 & 86.56 \\
\hline
\end{tabular}




\begin{tabular}{|c|c|c|c|c|c|c|c|c|c|}
\hline \multirow[b]{3}{*}{$\begin{array}{r}\text { Hypothesis of } \\
\text { equal variables } \\
S_{\alpha}=S_{\beta} \text { : }\end{array}$} & \multirow{2}{*}{\multicolumn{2}{|c|}{$\begin{array}{c}\text { Levene's test } \\
\text { for the equality } \\
\text { of variances }\end{array}$}} & \multicolumn{7}{|c|}{ Independent samples $t$-test for the equality of means } \\
\hline & & & \multirow[b]{2}{*}{$\mathrm{t}$} & \multirow[b]{2}{*}{ d.f. ${ }^{(b)}$} & \multirow[b]{2}{*}{ Sig. ${ }^{(c)}$} & \multirow[b]{2}{*}{$\begin{array}{c}\text { Mean } \\
\text { difference } \\
\langle\Delta \mu\rangle\end{array}$} & \multirow[b]{2}{*}{$\begin{array}{l}\text { SE of the } \\
\text { difference }\end{array}$} & \multicolumn{2}{|c|}{$\begin{array}{l}95 \% \text { confidence interval } \\
\text { for the mean difference }\end{array}$} \\
\hline & $\mathrm{F}$ & Sig. & & & & & & $\begin{array}{l}\text { Lower } \\
\text { limit }\end{array}$ & Upper limit \\
\hline \multicolumn{10}{|c|}{ PORTS (Number of ports included in each prefecture) } \\
\hline assumed & .008 & .930 & .456 & 33 & .651 & 1.07 & 2.34 & -3.69 & 5.82 \\
\hline$n_{2} \quad$ assumed & .842 & .366 & 1.083 & 31 & .287 & 2.31 & 2.13 & -2.04 & 6.65 \\
\hline \multicolumn{10}{|c|}{ IPP (Volume of economic activities that a prefecture has access to) } \\
\hline $\begin{array}{lr}n_{1} & \begin{array}{r}\text { not } \\
\text { assumed }\end{array}\end{array}$ & 4.413 & (f) & -3.856 & 36.065 & .000 & -19.52 & 5.06 & -29.78 & -9.25 \\
\hline $\begin{array}{rr}n_{2} & \text { not } \\
\end{array}$ & 4.783 & (f) & -3.843 & 32.107 & .001 & -20.57 & 5.35 & -31.48 & -9.67 \\
\hline \multicolumn{10}{|c|}{ DPP (Volume of economic activities developed within a prefecture) } \\
\hline $\begin{array}{lr}n_{1} & \text { not } \\
& \text { assumed }\end{array}$ & 4.530 & (f) & -2.227 & 26.478 & .035 & -40.49 & 18.18 & -77.83 & -3.16 \\
\hline$n_{2} \quad$ assumed & .979 & .327 & -3.688 & 47 & .001 & -17.60 & 4.77 & -27.19 & $\mathbf{- 8 . 0 0}$ \\
\hline \multicolumn{10}{|c|}{ GDP (Gross Domestic Product of each prefecture) } \\
\hline $\begin{array}{lr}n_{1} & \text { not } \\
& \text { assumed }\end{array}$ & 4.756 & $(\mathrm{f})$ & -1.567 & 25.336 & .129 & -2.28 & 1.45 & -5.27 & 0.71 \\
\hline assumed & .344 & .560 & -2.667 & 47 & .010 & -0.47 & 0.18 & -0.83 & -0.12 \\
\hline \multicolumn{10}{|c|}{$A_{S E C}(A$-sector specialization of each prefecture $)$} \\
\hline$n_{1} \quad$ assumed & 2.669 & .109 & -1.350 & 49 & .183 & -0.02 & 0.02 & -0.06 & 0.01 \\
\hline assumed & 1.327 & .255 & -2.081 & 47 & .043 & -0.03 & 0.02 & -0.07 & $\mathbf{0 . 0 0}$ \\
\hline \multicolumn{10}{|c|}{$C_{S E C}(C$-sector specialization of each prefecture $)$} \\
\hline $\begin{array}{lr}n_{1} & \text { not } \\
& \text { assumed }\end{array}$ & 3.048 & (f) & 4.876 & 43.903 & .000 & 0.14 & 0.03 & 0.08 & $\mathbf{0 . 2 0}$ \\
\hline assumed & 2.150 & .149 & 5.517 & 47 & .000 & 0.15 & 0.03 & $\mathbf{0 . 1 0}$ & 0.21 \\
\hline \multicolumn{10}{|c|}{$T_{G D P}$ (Tourism specialization of each prefecture) } \\
\hline $\begin{array}{rr}n_{1} & \text { not } \\
& \text { assumed }\end{array}$ & 3.034 & (f) & -.934 & 27.856 & .358 & -151.16 & 161.88 & -482.84 & 180.51 \\
\hline $\begin{array}{rr}n_{2} & \text { not } \\
\text { assumed }\end{array}$ & 6.780 & (f) & 1.244 & 28.060 & .224 & 48.88 & 39.29 & -31.58 & 129.35 \\
\hline \multicolumn{10}{|c|}{$A G R_{I N V}$ (Agro-industrial investments in each prefecture) } \\
\hline $\begin{array}{lr}n_{1} & \begin{array}{r}\text { not } \\
\text { assumed }\end{array}\end{array}$ & 4.100 & (f) & -1.355 & 31.346 & .185 & -0.96 & 0.71 & -2.40 & 0.48 \\
\hline $\begin{array}{rr}n_{2} & \text { not } \\
& \text { assumed }\end{array}$ & 3.981 & (f) & -1.316 & 28.152 & .199 & -0.99 & 0.75 & -2.52 & 0.55 \\
\hline \multicolumn{10}{|c|}{ RPD (Regional Productivity Dynamism) } \\
\hline $\begin{array}{r}\text { not } \\
\text { assumed }\end{array}$ & .011 & .915 & -3.237 & 49 & .002 & -8.80 & 2.72 & -14.26 & -3.33 \\
\hline $\begin{array}{rr}n_{2} & \text { not } \\
\text { assumed }\end{array}$ & .003 & .955 & -2.912 & 47 & .005 & -8.11 & 2.79 & -13.71 & -2.51 \\
\hline \multicolumn{10}{|c|}{ POP (Regional population) } \\
\hline $\begin{array}{lr}n_{1} & \text { not } \\
& \text { assumed }\end{array}$ & 4.402 & $(\mathrm{f})$ & -1.587 & 25.411 & .125 & -242064.4 & 152541.14 & $-555^{\prime} 971.2$ & $71^{\prime} 842.45$ \\
\hline assumed & .630 & .431 & -3.009 & 47 & .004 & -55964.64 & 18596.66 & $-93,376.30$ & $-18,553$ \\
\hline \multicolumn{10}{|c|}{ WELF (Regional welfare level) } \\
\hline assumed & .021 & .885 & 1.497 & 49 & .141 & 8.32 & 5.56 & -2.85 & 19.49 \\
\hline assumed & 1.787 & .188 & 2.449 & 47 & .018 & 12.14 & 4.96 & 2.17 & 22.11 \\
\hline \multicolumn{10}{|c|}{ EDU (Regional educational level) } \\
\hline assumed & 1.372 & .247 & -.366 & 49 & .716 & -1.78 & 4.86 & -11.55 & 7.99 \\
\hline$n_{2} \quad$ assumed & 2.512 & .120 & 1.364 & 47 & .179 & 3.84 & 2.82 & -1.82 & 9.51 \\
\hline URB (Regional ur & anization & vel) & & & & & & & \\
\hline assumed & .257 & .614 & 1.129 & 49 & .264 & 6.62 & 5.86 & -5.16 & 18.41 \\
\hline$n_{2} \quad$ assumed & .228 & .635 & .909 & 47 & .368 & 5.45 & 6.00 & -6.61 & 17.51 \\
\hline$R$ (TALC growth c & efficient $f$ & the $n u$ & iber of to & trists) & & & & & \\
\hline $\begin{array}{lr}n_{1} & \text { not } \\
\text { assumed }\end{array}$ & 24.714 & (f) & 3.564 & 33.094 & .001 & 0.00 & 0.00 & $\mathbf{0}_{+}$ & $\mathbf{0}_{+}$ \\
\hline $\begin{array}{rr} & \text { not } \\
n_{2} & \text { assumed }\end{array}$ & 21.799 & (f) & 3.487 & 34.295 & .001 & 0.00 & 0.00 & $\mathbf{0}_{+}$ & $\mathbf{0}_{+}$ \\
\hline T (TALC growth & fficient & r the $n$ & ber of & ists) & & & & & \\
\hline$n_{1} \quad$ assumed & .244 & .624 & .197 & 49 & .845 & 188.27 & 956.57 & $-1^{\prime} 734.02$ & 2'110.57 \\
\hline
\end{tabular}




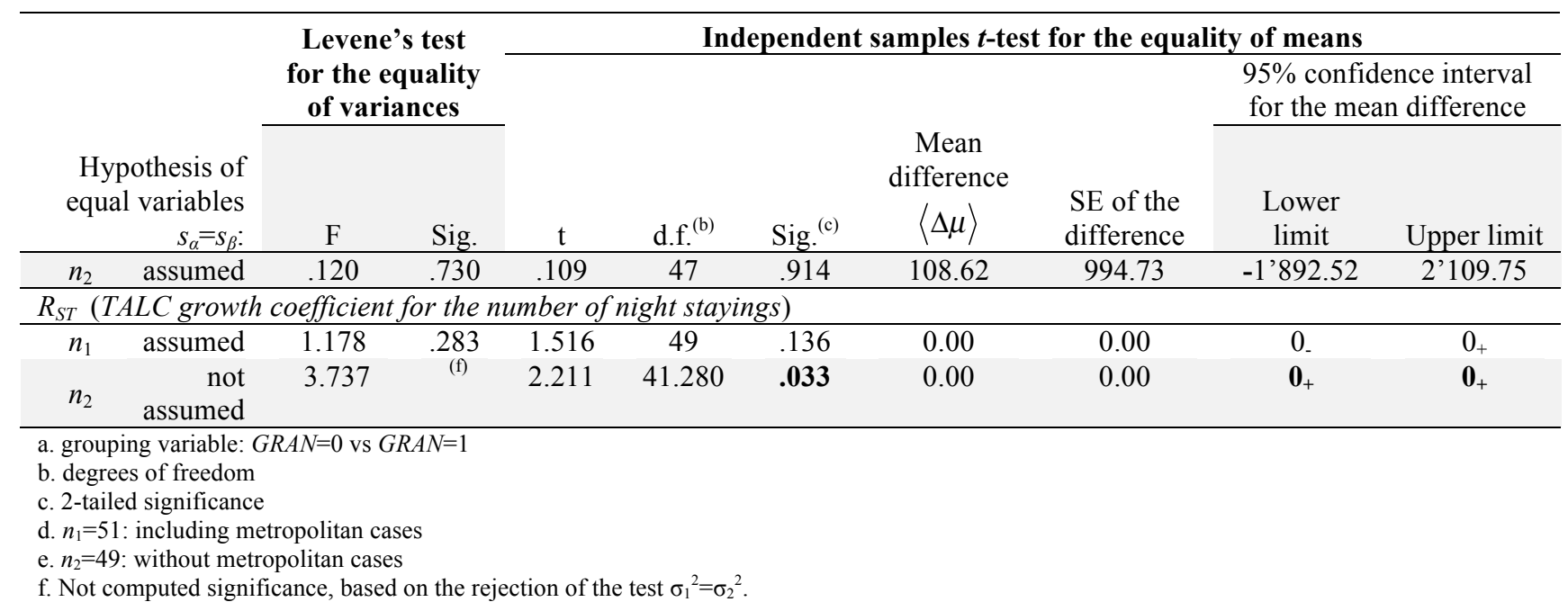

According to the results of table 5, the following observations can be made:

- The prefectures with railway network do not have longer road network (variable $G R N_{L E N G T H}$ ) than the others. This implies that the railway and road transportation do not share competitive roles.

- The prefectures with railway network are of greater area (variable AREA) than the others, a fact that is probably related to the massiveness of this transportation mode (train) and illustrates that railway infrastructures tend to be developed in sized regions. From another perspective, this result implies that a primary developmental force of railway network in Greece was the connection of land regions to promote agricultural productivity.

- The non-metropolitan regions $\left(\mathrm{n}_{2}=49\right)$ with railway infrastructure have lower road network density $\left(G R N_{D E N}\right)$ than the prefectures that do not have railway network. This result illustrates the competitive role of railway and road network in the Greek territory (excluding metropolitan cases). This observation, in conjunction with the previous concerning the variable $G R N_{L E N G T H}$, illustrates that the metropolitan regions seem to enjoy both (road and railway) facilities and, due to their size, to counterbalance this competitiveness.

- The existence of railway network appears unrelated to the number of ports included in each prefecture (PORTS) and thus to the Greek maritime transportation.

- The regions with railway network have greater indirect population potential (IPP) than the others, which implies that they have better accessibility to the economic activities of the other prefectures and thus better potential to regional growth.

- Similarly, the prefectures with railway network have greater direct population potential (DPP) than the others and thus better accessibility to the economic activities being developed within their region.

- The existence of railway infrastructure is related to the regional domestic product $(G D P)$ just for the case of non-metropolitan prefectures $\left(n_{2}=49\right)$. In particular, the regions of the Greek territory with railway network appear higher GDP values than the others, a result that verifies the general interactive role between regional development and transportation (Polyzos, 2011), but it also illustrates an outdated growth model between transportation and regional development in Greece, which is probably immanent from the industrialization era, where the railway infrastructure was a fundamental factor of regional development.
- Also, for the non-metropolitan case $\left(\mathrm{n}_{2}=49\right)$, the existence of railway infrastructures is related to the regional primary productivity specialization $\left(A_{S E C}\right)$. Particularly, the regions of the Greek territory that have railway network appear to be more specialized in the primary sector than the other regions. This observation, despite that it does not suffice to document causality, implies that railway infrastructures of the country facilitate agricultural productivity. From the planner's perspective, this result interprets that a major criterion for the railway network's design in Greece (initiated at the late 1860s) was obviously to facilitate the regional development, which was supported mainly by the primary sector at that time. Capturing such information from a modern socioeconomic data set, illustrates that the productivity basis in the regions of the Greek territory remained constant and controlled by the primary sector, which although is a positive insight in terms of stability it necessitates examination, as a further research, in terms of evolution.

- Complementary to the previous observation, the regions with railway network are less specialized to the tertiary sector $\left(C_{S E C}\right)$ than the others, which validates the outcome of the test for the variable $A_{S E C}$ and its relevant interpretations.

- The existence of railway infrastructures appears to be unrelated to the tourism specialization $\left(T_{G D P}\right)$, implying that the Greek tourism is supported by other transportation modes that are obviously more modern than rail transport.

- Further, the existence of railway network appears unrelated to the distribution of the agro-industrial investments $\left(A G R_{I N V}\right)$, despite that it is found to be related with the regional primary specialization $\left(A_{S E C}\right)$. This result is an aspect of complexity ruling the agro-industrial investments in Greece, which seems not to follow the traditional model of "regional development-transportation" that described the $t$-test results for the variable $A_{S E C}$.

- The prefectures with railway infrastructures present better performance in regional productivity dynamism $(R P D)$, verifying the observation about the contribution of the railway network to the regional growth.

- Next, the existence of railway network is related to regional population (POP) just for the non-metropolitan case $\left(n_{2}=49\right)$. Specifically, the regions of the Greek territory with railway network appear denser in population than the others, illustrating that the GRAN structure is gravity controlled. The fact that the metropolitan case $\left(n_{1}=51\right)$ does not provide significant results seems to be more due to heterogeneity in magnitude of metropolitan cases that 
increase the range of the confidence intervals rather than of any other physical interpretation, since the metropolitan regions are denser in population than others.

- In accordance with the population case, the existence of railway infrastructures appears to be related to the welfare index $(\mu \varepsilon \tau \alpha \beta \lambda \eta \tau \eta \dot{~} W E L F)$, also just in the nonmetropolitan case $\left(n_{2}=49\right)$. This result expresses that the regions of the Greek territory with railway network are less prosperous than the others, which implies the low "quality" level of services related to railway transportation.

- The existence of railway network is unrelated both to the educational level of population (EDU) and to the urbanization index (URB) of the prefectures. This seems reasonable, whether taking into consideration that the railway is a mode of massive transport that is accessible to all socioeconomic layers, whereas $E D U$ and $U R B$ are variables related to higher level of social activation.

- The prefectures with railway infrastructures appear more tourism saturated $(R)$ than the others. This result, in conjunction with the unrelated behavior captured for the variable of tourism specialization $\left(T_{G D P}\right)$, implies that while the GRAN is a transportation mode serving tourism, this functionality does not succeed to be profitable to the regions equipped with the railway facility.

- The existence of railway network appears unrelated to the TALC growth coefficient for the number of tourists $\left(R_{T}\right)$, which complies with the previous result and implies that although the transportation infrastructures in the country of destination serve tourism, they do not suggest a tourist attraction by themselves.

- Finally, the railway network is related to the TALC growth coefficient for the number of overnight stayings $\left(R_{S T}\right)$, just for the non-metropolitan case $\left(n_{2}=49\right)$. This result expresses that the tourists visiting Greece prefer to stay less days to regions of the Greek territory that have railway infrastructure than those they do not have. This may imply that the regions with railway network are more specialized in tourism by providing transportation services than to offer any other attraction or leisure facilities.

\section{Conclusions}

This paper studied the Greek railway transportation network by using complex network analysis and empirical approach. The purpose of the study was to detect the socioeconomic information immanent to the GRAN's topology and to provide insights about how the network structure of this transportation network serves and promotes regional development. The GRAN was constructed in the $L$-space representation as a non-directed graph, where nodes represent route intersections and edges express intermediate railway routes. The topological analysis showed that GRAN is submitted to obvious spatial constraints, which were evident by the peaked shape of the degree distribution, the resemblance of the GRAN's spy plot with this of a lattice- like null model, the lattice-like indication of the $\omega$-index (for the small-world property approximate detection), the typology of the correlations $\left(k, C^{b}\right)$ and $(k, s)$, the geographical coherence of the community detection, and the patterns revealed in the spatial distribution of the fundamental network measures.

The topology of the GRAN appeared to share lattice-like characteristics, which are consequent to the spatial structure of this network. However, certain findings, such as the inequality detected between the average degree and average nearest neighbor degree, the spatial distribution of the measures of degree and closeness centrality, and the powerlaw exponent of the correlation $\left(k, C^{b}\right)$ provided indications that the topology of this railway network is better than a lattice and resembles to a bus-like topology.

The empirical analysis was applied to a set of nodevariables (with elements values computed for each node) of the GRAN, with network, spatial, economic, demographic, and tourism information. In order to detect the influence that the metropolitan regions (population > one million) of Attica and Thessaloniki have to the configuration and functionality of railway transportation in Greece, the empirical analysis was separated into two parts; the first including in the variables the metropolitan cases and the second excluding them. Afterwards, an independent-samples $t$-test was applied for each part, by grouping the variables to cases including a railway network and to those they not include railway infrastructures.

The results showed that railway infrastructures in Greece are developed in sized regions, support access to own and other regions' economic activities, operate competitively to tertiary specialization, and although they serve tourism they do not provide tourism specialization. Especially for the Greek territory (non-metropolitan case), regions with railway infrastructure have greater population but less road network density, are more specialized to the primary productivity sector, are less prosperous than others, and are related to tourism more by providing transportation services than to offer any other attraction or leisure facilities.

Overall, the analysis provided evidence for the utility of complex network analysis in regional and spatial studies, showing that the GRAN enjoys an effective architecture of bus-topology, but its socioeconomic functionality is not as effective as its topology. The railway infrastructures in Greece seemed to follow an outdated growth model related to the support of primary productivity, but without promoting the welfare of their regions equivalently. This finding should alert the policy makers to focus on the direction of upgrading the railway facilities in order not only to be profitable, but also to facilitate the way of living.

This is an Open Access article distributed under the terms of the Creative Commons Attribution Licence

\section{References}

1. Albert, R., Barabasi A-L., (2002) "Statistical mechanics of complex networks", Review of Modern Physics, 74(1), pp.47-97.

2. Barabasi, A-L., Albert, R., (1999) "Emergence of Scaling in Random Networks", Science, 286(5439), pp.509-512.
3. Barrat, A., Barthélemy, M., Vespignani, A., (2005) "The effects of spatial constraints on the evolution of weighted complex networks, Journal of Statistical Mechanics, P05003.

4. Barthelemy, M., (2011) "Spatial networks", Physics Reports, 499, pp.1-101. 
5. Bishop, C. M., (2006) Pattern Recognition and Machine Learning, Singapore, Springer Science and Business Media.

6. Google Maps, (2013) "Google Mapping Services", available at the URL: www.google.gr/maps?hl=el [last accessed: 29-8-2013]

7. Hays, L., (1981) Statistics (3rd ed.), New York, Holt, Rinehart and Winston Publications.

8. Hu, Y., Zhu, D., (2009) "Empirical analysis of the worldwide maritime transportation network", Physica A, 388, pp.2061-2071.

9. Kurant, M., Thiran, P., (2006) "Extraction and analysis of traffic and topologies of transportation networks", Physical Review E, 74, 036114.

10. Lands and Mapping Agency of Greece - OKXE, (2005) «Road Network DMEO», available at the URL: http://www1.okxe.gr/ geonetwork/ srv/ en/ google.kml?uuid=19226ad1-1297-40418cea-3aa45a2b5f4e\&layers=rdndmeo [accesed: 07-03-2015].

11. Maslov, S., Sneppen, K., (2002) "Specificity and stability in topology of protein networks", Science, 296, pp.910-913.

12. Norusis, M., (2004) SPSS 13.0 Statistical Procedures Companion, New Jersey, USA,

13. Polyzos, S., (2011) Regional Development, Athens, Greece, Kritiki Publications [in Greek].

14. Polyzos, S., Tsiotas, D., Kantlis, A., (2013) "Determining the Tourism Developmental Dynamics of the Greek Regions, by using TALC Theory", TOURISMOS: an International Multidisciplinary Journal of Tourism, 8(2), pp.159-178.

15. Polyzos, S., Tsiotas, D., Niavis, S., (2015) "Analyzing the Location Decisions of Agro Industrial Investments in Greece", International Journal of Agricultural and Environmental Information Systems, 6(2), pp.77-100.

16. Polyzos, S., Tsiotas, D., Papagiannis, K., (2014) "Determining the changes in commuting after the Ionian Motorway's construction", MIBES Transactions, 8, pp. 113.
17.Porter, M. A., (2012) "Small-world network", Scholarpedia, 7(2), doi:10.4249/scholarpedia.1739.

18. Prentice Hall Publications.

19. Public Data, Open Data - geodata.gov.gr (2010), «Railway network of Greece», unique reference number: 37468daf-d548-49f7-bce955b77661ea63 [accessed: 07-03-2015].

20. Rodrigue, J. P., Comtois, C. \& Slack, B. (2013) The Geography of Transport Systems. New York: Routledge Publications.

21. Rubinov, M., Sporns, O., (2010) "Complex network measures of brain connectivity: uses and interpretations", Neuroimage, 52, pp.1059-1069.

22. Sen, P., Dasgupta, S., Chatterjee, A., Sreeram, P. A., Mukherjee, G., Manna, S. S., (2003) world properties of the Indian railway network, Physical Review E67, 036106.

23. Sgroi, D., (2008) "Social network theory, broadband and the future of the World Wide Web", Telecommunications Policy, 32, pp.6284.

24. Stumpf, M. P., Porter, M. A., (2012) "Critical truths about power laws”, Science, 335, doi:10.1126/science.1216142.

25. Tsiotas, D., Polyzos, S., (2015) "Analyzing the maritime transportation system in Greece: a complex network approach", Networks and Spatial Economics, 15(4), pp.981-1010.

26. Tsiotas, D., Polyzos, S., (2015) "Decomposing multilayer transportation networks using complex network analysis: a case study for the Greek aviation network", Journal of Complex Networks, 3(4), pp.642-670.

27.Heymann, S., (2014) "Gephi", in Alhajj, R., Rokne, J., (Eds) Encyclopedia of social network analysis and mining, New York, Springer, pp.612-625. 